\title{
Sideroblastic anaemia with iron overload presenting as an arthropathy
}

\author{
M. A. FITZCHARLES, J. R. KIRWAN, B. T. COLVIN,* AND H. L. F. CURREY \\ From the Bone and Joint Research Unit and ${ }^{*}$ Department of Haematology, The London Hospital
}

SUMMARY We report on 2 patients with sideroblastic anaemia and secondary iron overload whose presenting symptom was an arthropathy of small and large joints. One patient had marked spinal symptoms which were severe enough to suggest ankylosing spondylitis, and the pattern of arthritis in the other resembled seronegative rheumatoid arthritis. We believe these to be the first cases described of an arthropathy associated with iron overload secondary to sideroblastic anaemia.

\section{Case reports}

\section{CASE 1}

A 32-year-old Anglo-Asian man presented with a 7-year history of intermittent arthralgia involving the metacarpophalangeal (MCP) and metatarsophalangeal (MTP) joints, elbows, shoulders, and knees. At the onset of his symptoms he was noted to be anaemic, but received no treatment for anaemia or joint symptoms. During the previous year his joints had become increasingly painful, and the MCP and right knee joints had become swollen. Lumbar backache, which disturbed sleep at night, and morning stiffness of the whole spine frequently lasting for up to 5 hours a day, had become prominent and disabling complaints.

There was no history of any bowel, genitourinary, or ocular disturbance. A varicose ulcer on the medial aspect of the left leg had healed well following a varicose vein operation and there were no other skin lesions. The only symptom of anaemia or cardiovascular disease was breathlessness on exertion. There was no family history of any joint or haematological disease, and there had been no exposure to any medications or toxins.

Examination showed a pale man of normal build, with normal pigmentation and secondary sexual characteristics. The liver was palpable at $5 \mathrm{~cm}$ and the spleen at $4 \mathrm{~cm}$ below the costal margins. MTP and MCP joints were tender but not swollen.

The haemoglobin was $8.6 \mathrm{~g} / \mathrm{dl}$ with a mean corpuscular volume (MCV) of $61 \mathrm{fl}$, mean corpusArthritis and Rheumatism Council Building, 25-29 Ashfield Street, London E1 2AD. cular haemoglobin $(\mathrm{MCH})$ of $17 \mathrm{pg}$, and mean corpuscular haemoglobin concentration (MCHC) $28 \mathrm{~g} / \mathrm{dl}$. The white cell count was $5 \cdot 8 \times 10^{9} / 1$ with a normal differential and a platelet count of $181 \times 10^{9} / 1$. The reticulocyte count was $1 \cdot 8 \%$.

The peripheral blood smear showed a dimorphic picture with hypochromia and microcytosis compatible with sideroblastic anaemia. This was confirmed on bone marrow examination, which revealed increased erythropoiesis, large amounts of iron in marrow fragments, and numerous ring sideroblasts. The serum iron was $66 \mu \mathrm{m} / 1$ (normal 14-30 $\mu \mathrm{m} / \mathrm{l}$ ) and the total iron binding capacity $67 \mu \mathrm{m} / 1$ (normal 44-67 $\mu \mathrm{m} / \mathrm{l}$ ). Serum ferritin was $3000 \mu \mathrm{g} / \mathrm{l}$ (normal $10-250 \mu \mathrm{g} / \mathrm{l})$. Haemoglobin electrophoresis was normal. The ESR was $2 \mathrm{~mm} /$ hour, latex test for rheumatoid factor was negative, antinuclear antibody test (ANA) negative, serum folate $4 \cdot 6 \mu \mathrm{g} / \mathrm{l}$, and serum $B_{12} 490 \mathrm{pg} / \mathrm{l}$. Liver function tests, glucose tolerance test, electrocardiogram, and $x$-rays of the chest, hands, and feet were normal. $X$-rays of the lumbar spine showed only multiple Schmorl's nodes.

Treatment was started with pyridoxine $300 \mathrm{mg}$ daily, and there was a reticulocyte count of $11.2 \%$ and a rise in haemoglobin of $2.7 \mathrm{~g} / \mathrm{dl}$ within one week. The joint pains and morning stiffness were unresponsive to a variety of nonsteroidal antiinflammatory agents and analgesics. Venesection was performed at monthly intervals in an attempt to correct the iron overload. The peripheral blood is still hypochromic and dimorphic and the spleen remains enlarged.

\section{CASE 2}

In 1976 a 68-year-old Caucasian woman presented with a 2-year history of intermittent neck pain with stiffness and mild polyarthralgia of the hands. She 
had no other symptoms. Her ESR was $24 \mathrm{~mm}$ /hour, latex test for rheumatoid factor negative, and ANA negative. Cervical spine $x$-rays showed marked spondylosis, and she was treated with physiotherapy. Her haemoglobin was $10.3 \mathrm{~g} / \mathrm{dl}, \mathrm{MCV} 99 \mathrm{fl}, \mathrm{MCH}$ $33.2 \mathrm{pg}$, MCHC $34.7 \mathrm{~g} / \mathrm{dl}$, reticulocyte count $2 \%$, serum iron $33 \mu \mathrm{m} / \mathrm{l}$, serum iron binding capacity $73 \mu \mathrm{m} / 1$, serum folate $13 \mu \mathrm{g} / \mathrm{l}$, red cell folate 431 $\mu \mathrm{g} / \mathrm{l}$, and $\mathrm{B}_{12}$ greater than $600 \mathrm{pg} / \mathrm{l}$. A Coombs test was negative, and a bone marrow aspirate showed increased erythropoiesis, slightly increased iron stores, and occasional ring sideroblasts.

Over the following 18 months she complained of recurrent mild polyarthralgia and intermittent low back pain and took indomethacin as required. In spite of treatment with pyridoxıne $300 \mathrm{mg}$ daily and folic acid there was no change in haemoglobin, MCV, or serum iron binding capacity. Serum iron, however, rose to $40 \mu \mathrm{m} / \mathrm{l}$. A second bone marrow aspirate showed increased erythropoiesis, markedly increased iron stores, and numerous ring sideroblasts.

For the next 2 years there was little change in her symptoms or the anaemia. In July 1979 she developed the first signs of an inflammatory polyarthritis, with swelling of the wrists and 2nd and 3rd MCP joints of both hands and tenderness of the left ulnar styloid. Her anaemia remained unchanged, but her ESR rose to $33 \mathrm{~mm} /$ hour. Latex test for rheumatoid factor remained negative, and $x$-rays then and 6 months later (when she had an obvious symmetrical polyarthritis with involvement of all the joints of the hands and an hour of morning stiffness) showed no bony abnormalities.

By April 1980 her widespread polyarthritis and severe morning stiffness necessitated admission to hospital. Investigations showed an ESR of 60 $\mathrm{mm} /$ hour, tests for rheumatoid factor and ANA negative, haemoglobin $8 \cdot 8 \mathrm{~g} / \mathrm{dl}$, MCV $100 \mathrm{fl}$, serum iron $21 \mu \mathrm{m} / 1$, serum iron binding capacity $66 \mu \mathrm{m} / 1$, serum ferritin $500 \mu \mathrm{g} / \mathrm{l}$, serum $B_{12} 480 \mathrm{pg} / \mathrm{l}$, serum folate greater than $28 \mu \mathrm{g} / \mathrm{l}$ and red cell folate greater than $560 \mu \mathrm{g} / \mathrm{l}$. A further bone marrow aspirate showed a considerable increase in erythropoiesis, markedly increased iron stores, and gross sideroblastic change.

She improved with bed rest, piroxicam, and subsequent mobilisation, but her anaemia remained refractory to treatment.

\section{Discussion}

Arthritis is a well recognised feature of idiopathic haemochromatosis. ${ }^{1-3}$ It tends to be symmetrical and progressive, affecting first small then larger joints. Generally the features are those of a degenera- tive arthropathy, but acute inflammatory episodes may also occur. Radiological chondrocalcinosis is a common accompaniment, and synovial iron deposits reflect total body iron overload. Removal of excess iron, however, does not help the joints. Although the pathogenesis of this arthritis is not understood, and the role of neither iron nor calcium pyrophosphate deposits is clear, it appears to result not from the underlying defect in idiopathic haemochromatosis but from the resulting iron overload. Thus it has also been described in association with the iron overload of repeated blood transfusions ${ }^{4} 5$ and hereditary spherocytosis. ${ }^{6}{ }^{7} \mathrm{We}$ are not aware of its having been described previously in association with the iron overload of sideroblastic anaemia.

The 2 cases reported here undoubtedly suffered from sideroblastic anaemia with iron overload, and in neither case was an underlying cause for the sideroblastosis found. Case 1 showed the characteristic progression from a small joint arthropathy to a more disabling arthritis affecting larger joints. He then developed spinal pain with morning stiffness and immobility sufficiently severe to mimic ankylosing spondylitis. However, there were no radiological signs to support the latter diagnosis, and it appears likely that this was a feature of an iro용 overload arthropathy. Spinal symptoms are uns common in haemochromatosis, although calciur pyrophosphate deposition and other changes have been described in the ligamentum flavum and intervertebral discs. ${ }^{8}$

Case 2 presented features which would have suggested seronegative rheumatoid arthritis, had they not appeared simultaneously with the development of sideroblastic anaemia and iron overload. The arthritis of haemochromatosis is frequently mistaken for rheumatoid arthritis, ${ }^{3}$ and it appears likely (although not proved) that this also is an example of iron overload arthropathy. Neither of these 2 patients showed the radiological chondrocalcinosis which Dymock and his colleagues ${ }^{6}$ found in 25 out of 31 patients with haemochromatosis arthropathy.

We thank Dr G. O. Storey for permission to report the second case.

\section{References}

1 Schumacher H R. Haemochromatosis and arthritis. Arthritis Rheum 1964; 7: 41-50.

2 Delbarre F. Les manifestations ostéo-articulaires de l'hémochromatose. Presse med 1964; 72: 2973-8.

3 Hamilton E, Williams R, Barlow K A, Smith P M. Arthropathy of idiopathic haemochromatosis. $Q \mathrm{~J} \mathrm{Med}$ $1968 ; 37: 171-82$. 
4 Abbot D F, Gresham G A. Arthropathy in transfusional siderosis. Br Med J 1972; i: 418-9.

5 Sella E J, Goodman A G. Arthropathy secondary to transfusion haemochromatosis. J Bone Joint Surg 1973; 55A : 1077-81.

6 Dymock I W, Hamilton E B D, Laws J W, Williams R. Arthropathy of haemochromatosis. Clinical and radio- logical analysis of 63 patients with iron overload. Ann Rheum Dis 1970; 29: 469-76.

7 Berry E M, Miller J P. Hereditary spherocytosis, haemochromatosis, diabetes mellitus and chondrocalcinosis. Proc $R$ Soc Med 1973; 66: 9-10.

8 Bywaters E G L, Hamilton E B D, Williams R. The spine in idiopathic haemochromatosis. Ann Rheum Dis 1971; 30: 453-65. 